\title{
Comparison of language development with motor development in active and inactive children (Case study: Children 5 to 8
} years old)

\author{
Mohammadbagher Forghani Ozrudi (i)
}

Physical Education Teacher, Education Office, Babol, Iran.

\begin{abstract}
The object of this study was to determine the relation of language development to motor development in active and non-active children in 5-8 years old. The research universe included all boy students from 5 to 8 years old in Babol city and 120 persons were selected clustered randomly as a research sample. measurement instrument includes personal information questionnaire, children bodily activity amount questionnaire, Rion intelligent test, Ulrich great motor development test, Lincoln-Ozertsky tiny motor development test, language development test (ptold:3). In order to analyze the data, Pearson correlation coefficient and independent t-test were used. The results showed that there was a relation between language development and movement and this relation was more meaningful for 6-5 years old between language development and great movement and 7-8 year's old in tiny motor development. There was no meaningful relation between language development and movement in active and nonactive children. The results showed a close relationship between language development and motor development in childhood and are influenced by each other.
\end{abstract}

Keywords. Active and non-active children, language development, motor development.

\section{Introduction}

Although, there is increasingly human knowledge about humans and their different aspects in recent years, to determine growth procedure and human evolution as a multi-dimensions phenomenon and emphasize the integrated and general growth of humans, but we could say there is little attention to movement behavior role as one of the most important aspects of this procedure (Baghande et al., 2015). In this case, the state of movement behavior in human integrated growth especially mental growth and recognition is not as clear as it would be. Based on Piaget theory, the recognition growth procedure would be done continuously, and all aspects of life and mind are gradually in cooperation with movement during it, but according to Piaget's recognition growth procedure, we would state this cooperation is more obvious in childhood, especially in sensible-movement and proportionality procedure. In this case, according to Piaget's theory, a child thinks by his body more in the first stages of the recognition growth procedure (Pangrazi \& Beighle, 2019).

Children begin interaction with the environment from birth by unconscious and reflexive activity (Dehghanizade et al., 2018). Then, child movement gradually became conscious and is done by more knowledge. As a whole, although Piaget believes recognition growth and movement are interactive, movement's role in facilitating child learning is more obvious than adulthood (Piaget, 2015). Motor skills are considered important for children's physical, social, and psychological development. Pre-school age seems to be decisive for the development of motor skills (Gümüşdağ, 2019). In this case, it emphasizes even in youth and adolescence using movement development simplifies some contents understanding. Language development procedure as a recognition factor is an organized and continuous procedure in which

\footnotetext{
M. Forghani Ozrudi, e-mail: mohammadbagher.forghani@gmail.com Received: March 21, 2021 - Accepted: August 19, 2021 - Published: October 16, 2021

To Cite: Forghani Ozrudi, M. (2021). Comparison of language development with motor development in active and inactive children (Case study: Children 5 to 8 years old). Turk J Kinesiol, 7(3), 98-104. DOI: 10.31459/turkjkin.930474
} 
interferes with some different growth stages and in the growth procedure of language, different regions related to memory and movement development control are involved (Loprinzi \& Cardinal, 2011). Speech production is the result of combining and composing hearing information, sensing, and movement development in the mind. Also, speech as a movement development phenomenon requires ability in consecutive movement developments and speedy of talking organs. It seems between all human movement development activities, speech production is the more complicated one and naturally requires the tiniest and exact movement development skills (Burton \& Miller, 1998). All experts believe there is a relation between general movement development ability and skills in speech production phenomenon.

Much research has been done yet, there are so many different views in this regard. For example, Harrow (1983) has stated in a study, there is not enough observation to emphasize on existing the relation between production disorder and delay in tiny movement developments skills in children. Dworkin \& Richard (1985) denied the relationship between movement development growth and language development. Against, Jenabi et al. (2003) in a study have concluded there is a relation between the ability to do tiny movement development skills, to the intensity of speech disorder and the type of disorder. Gandotra et al. (2020) had emphasized the relation between movement development skills and disorder in production.

Payne \& Isaacs (2020) has stated in this regard: there is high relation between movement development growth and language development especially in childhood (before 2 years old). Also, language development's relation to movement development growth does not have any answer, yet. For example, Devinsky \& D'esposito (2003) has summarized so many studies in physiologic neurology in which have emphasized performance similarity of moving, imagination, speech, and its observance. Visscher et al. (2007) have stated a ball skill is the only difference between children by speech disorder and control. In another study, Meister (2003) has reached a strong correlation between hand movement region stimulation in the brain and speech. Whereas there is no relation between feet movement region stimulation and speech. Cheng et al. (2009) showed children with speech disorders were weak in hand and eyes coordination, too.
According to the past research and existing difference between researcher's findings, we tried to measure the amount of relation between movement development growth and language to reach language development from movement development growth or in language development, determine and program bodily activity and child movement development growth and suggest some programs for movement development growth in a speech cure center for exceptional children. Because childhood is very sensitive for growth, if there is any relation, we should pay special attention to programmed activity and codified to strengthen language and movement development growth in these eras. It is required because we reach movement development growth through language development, or we could anticipate it. Therefore, it is one of finding talents skills in order to reach future sportsmanship.

\section{Methods}

In this study, we have used correlation and comparingcausative method of descriptive type in which from object view is of basic and developing research. The research universe included all boy students in 5-8 years old and was educated in pre-school, one and second grades of Babol city. There were 9783 persons, and 120 participants were selected by the clustered randomly sampling, multi-phases, objectively for about 5 schools has been selected randomly. Then, because there was more than one class in every grade in this school, we selected randomly from every grade. The study was approved by the Ethics Committee of Mazandaran University of Science and Technology (Number: 8821/F.P, Date: 17 December 2020).

After determining classes, an introductory questionnaire was distributed between students in which has been compiled for sample selecting and sample matching. Also, about filling the questionnaire, the researcher guided students, managers, and sports teachers. This test involves grate degree of mental ability and is usable for all ages. This test has been customized by Farahani et al in the office of consultant and research in education and training ministry's assistant and the norm related to any province has been determined.

In order to measure the amount of bodily activity of children (based on existing facilities and children age limits in this study, we have used parent's reports in which its narration and stability were accepted. 
Because children of these ages are not able to report their bodily activity exactly. Therefore, it is better to ask parents about their bossy activities at these ages.

In this case, researchers tried to minimize different factors' influence except for independent variables and based on existing information tastes being matched based on intelligence, economic status, family, social and cultural and body status and bodily activity and the member of the family. At last, after study and examining information, about 120 students by similar condition has been selected for contributing to study and based on their activity has been divided into two groups of active and non-active and has been tested by:

1. Language development test (TOLD-P: 3) compiled by Newcomer and Hamill has been customized is based on a two-dimension model (Güven \& Topbaș, 2014). In one dimension, there are linguistic systems by listening, organizing, talking indicators, and in another dimension is linguistic characteristic by semantic, meaning, and phoneme indicators. Mentioned twodimension model is the theoretical basis of preparing 9 sub-tests. Six sub-tests are related to meaning, semantic and are from the basic sub-test and 3 subtests are related to phoneme and are of the supplementary test.

2. Linkoln-Ozertsky movement development growth test is for evaluating movement development ability of children in 5-14yeras old. It was performed individually and had 36 cases. Different movement development skills like toes skill, eye coordination, hand, knee, feet, and body were measured and determined. In this study, of 36cases, 8 cases were selected related to hand and feet movement development and were tested. Because we tried to test movement development ability, therefore, at first provided the information required to tastes and then even performed all movements to acknowledge children and we paid attention to children's fatigue, too.

3. To measure great movement development skills, we have used of Ulrich grate movement development test, the second edition to measure basic skills of tastes. This test does have 12 great movement development tests in which includes two sub-tests of substituting including run, trot, hopping, stretched step, horizontal jump, sliding, and subtests of object controlling like fix knocking to the ball, in place knocking, getting, knocking by feet, shooting above the shoulder, under rolling. This test is to measure great movement development performance in children 3-11 years old.
Test narration is $96 \%$ and its stability for sub-test is $87 \%$ and for great movement, development is $91 \%$.

Normality analyses were examined by KolmogorovSmirnov. The independent t-test was conducted to compare the groups. Pearson correlation coefficient was used to determine the relationship between the variables. The data were analyzed by using SPSS 22 . Significant level was set at $\mathrm{p} \leq 0.05$.

\section{Results}

Before analyzing datum, we have used descriptive statistics for categorizing, determining dispersion, and central indicators. In this case, according to Table 1 , at first, it has been determined the age of two groups and stated dispersion indicators and then compared the age of active and non-active groups.

\begin{tabular}{lcc}
$\begin{array}{l}\text { Table } 1 \\
\text { The statistical description of children's age. }\end{array}$ & \\
\hline Number & Valid & 120 \\
& Non & 0 \\
\hline Mean & & 6.9 \\
SE & 0.09 \\
SD & 1.08 \\
Amplitude & 3.8 \\
Min & 5.1 \\
Max & 8.9 \\
Quarters & & 6.1 \\
& 25 & 7 \\
\hline
\end{tabular}

Because childhood is a very sensitive age for growth and age differences could influence language and movement development growth, therefore, we examined the two active and non-active groups' age to know their differences (Table 2).

The result of data analysis showed there is a relation between language development and movement development and this relation is more meaningful in great movement development growth and language development in the years of 5-6 and for the ages of 7-8 is more meaningful to tiny movement development growth. There are no meaningful differences in active 
and non-active children between language and movement development growth.

According to Table 3, we could indicate: in 6-5 years old children, there is meaningful statistical relation between language development and great movement development ( $\mathrm{r}=.89 ; \mathrm{p}=0.001)$. Also, we could indicate there is meaningful statistical relation between language growth and tiny movement developments $(\mathrm{r}=.74 ; \mathrm{p}=0.001)$.

According to Table 4, there is meaningful statistical relation between language development and great movement development $(\mathrm{r}=.42 ; \mathrm{p}=0.001)$. Also, we could indicate there is meaningful statistical relation between language development and tiny movement development $(\mathrm{r}=.80 ; \mathrm{p}=0.001)$.

Table 2

The result of the comparison of the active and non-active groups.

\begin{tabular}{llcccccc}
\hline & Group & $\mathrm{n}$ & Mean & $\mathrm{SD}$ & $\mathrm{t}$ & $\mathrm{df}$ & $\mathrm{p}$ \\
\hline Age & Non active & 60 & 6.96 & 1.09 & 0.047 & 118 & 0.9 \\
& Active & 60 & 6.95 & 1.08 & & & \\
\hline
\end{tabular}

\section{Table 3}

The relationship between variables in 6-5 year's old children.

\begin{tabular}{lcc}
\hline Indicators & $r$ & $p$ \\
\hline Language development and great movement development & .89 & $0.001^{*}$ \\
Language development and tiny movement development & .74 & $0.001^{*}$ \\
\hline${ }^{*} p<0.05$ & &
\end{tabular}

\section{Table 4}

Result of relation test between variables by Pearson method in 7-8 years old children

\begin{tabular}{lll}
\hline Indicators & $r$ & $p$ \\
\hline Language development and great movement development & .42 & $0.001^{*}$ \\
Language development and tiny movement development & .80 & $0.001^{*}$ \\
\hline
\end{tabular}

$* p<0.05$

Table 5

Comparisons of the variables between active and non-active groups in 6-5 years old children.

\begin{tabular}{llcccccc}
\hline & Groups & $\mathrm{n}$ & Mean & $\mathrm{SD}$ & $\mathrm{t}$ & $\mathrm{df}$ & $\mathrm{p}$ \\
\hline Language Development & Non active & 30 & 61.0 & 14.8 & -0.4 & 58.0 & 0.7 \\
& Active & 30 & 62.5 & 15.6 & & & \\
Great Movement Development & Non active & 30 & 52.4 & 5.5 & -0.2 & 58.0 & 0.8 \\
& Active & 30 & 52.7 & 5.9 & & & \\
Tiny Movement Development & Non active & 30 & 15.0 & 1.3 & -0.9 & 58.0 & 0.4 \\
& Active & 30 & 15.4 & 1.9 & & & \\
\hline
\end{tabular}


Table 6

Result of difference test between variables by t-independent test in 7-8 years old children.

\begin{tabular}{llllllll|}
\hline & Groups & $\mathrm{n}$ & Mean & SD & $\mathrm{t}$ & $\mathrm{df}$ & $\mathrm{p}$ \\
\hline Language development & Non active & 30 & 80.0 & 6.0 & -0.7 & 58.0 & 0.5 \\
& Active & 30 & 81.2 & 6.8 & & & \\
Great movement development & Non active & 30 & 77.2 & 6.8 & -0.5 & 58.0 & 0.6 \\
& Active & 30 & 78.2 & 7.6 & & & \\
Tiny movement development & Non active & 30 & 17.1 & 2.9 & -0.5 & 58.0 & 0.7 \\
& Active & & 16.7 & 2.8 & & & \\
\hline
\end{tabular}

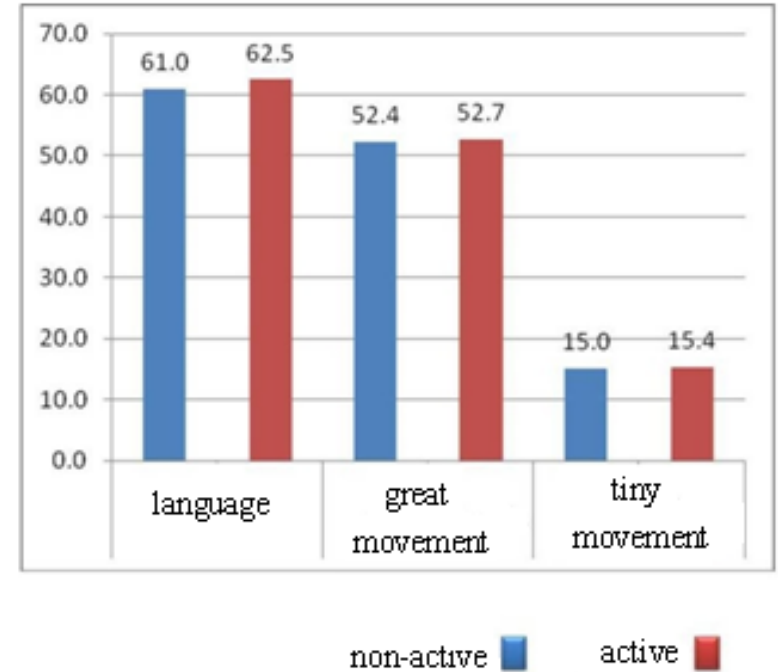

Figure 1. Comparisons of the language development and movement development in active and non-active 6-5 years old children, spontaneously.

According to Table 5, there is no meaningful difference between language development and movement development growth inactive and nonactive 5-6yeras old boys.

According to Table 6, there was no meaningful difference between language development and movement development growth in active and nonactive 7-8 years old boys.

Also, based on this study, there was high relation between language development and tiny and great movement development growth in 5-6 year's old children. In this age, the relation of language development to great movement development growth is more than tiny movement development. For the children in the age of $7-8$, there is high relation

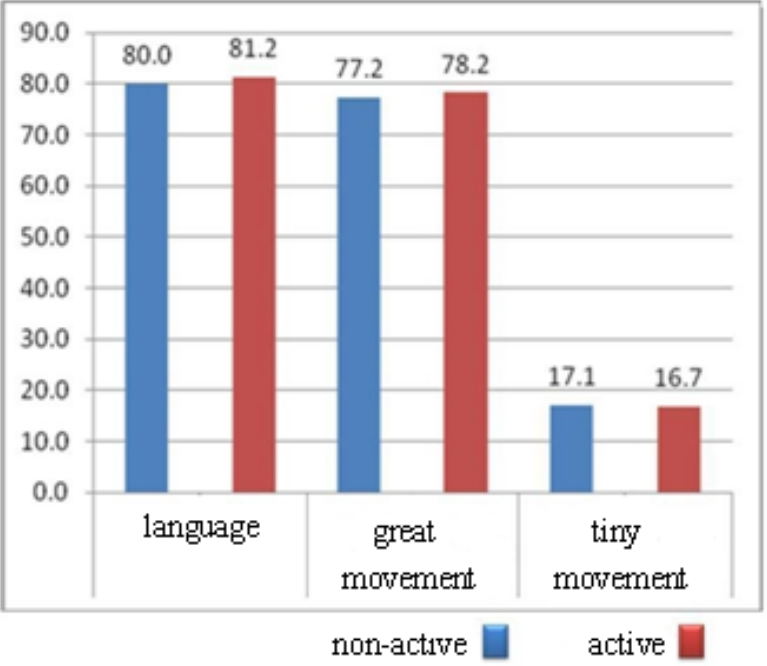

Figure 2. Comparisons of the language development and movement development in active and non-active 7-8 year's old children, spontaneously.

between language development and great and tiny movement development growth, and against 5-6 years old, there is more relation between language development and tiny movement development than great movement development growth. Also, the findings showed, there is no meaningful relation between language development and active and nonactive children in which has been shown in Figures 1 and 2 .

\section{Discussion}

Based on current study findings, there is high relation between language development and tiny and great movement development in 5-8yeras old children. 
Results of the study are parallel with Payne \& Isaacs (2020), and against Harrow (1983), Dworkin \& Richard (1985) research. Perhaps, the cause is high relation between limbic, basic and hearing, speech parts of the brain.

The one point in which its theoretical reason has been supported (static brain structure interaction, nervous performance, and learning). According to the age, in the children in the years of 5-6 language development related to great movement development growth is more than tiny movement development growth in which this finding is matched by Meister et al. (2003), Visscher et al. (2007). In the children in the years of $7-8$, the relation between tiny movement development growth and language development is more than great movement development growth and are matched by findings Jenabi et al. (2003), Cheng et al. (2009), and Visscher et al. (2007).

The cause is related to age and children's experience. Visscher et al. (2007) have found high relation of ball movement development growth to language development in the years of 6-9 and using more ball skills. Also, in this research, there is a meaningful difference between active and non-active children in movement development growth and language in which is opposed to before studies. Perhaps its causes include: The first one, those children in which were included in the non-active group, were none fully inactive, but the amount of their activity was less than the active group (For separating active from the non-active group, the activity score based on hours has been changed to the standard score and have included high and low standard deviation and an active and non-active). The least amount of activity is influential on different aspects of growth. The second factor is related to parents' UN correct reports of the amount of bodily activity of children. The third factor is related to researchers; however, the amount of bodily activity is different but is not an important and influential factor in the amount of activity. But the type of activity and objectivity is influential on movement development growth and language or only is losing time? It should not be forgotten that creating opportunities to practice age-appropriate play in childhood, especially with the participation and support of parents, has positive effects on motor development (Cheraghi et al., 2021).

In reviewing studies that have been performed in foreign countries, we concluded children's activity was done by programming and in order to promote growth level and unfortunately has been ignored in our country. There are three factors for children to practice time for growing understanding-movement development skills including facilities, equipment, and time. Unfortunately, practice times are limited by the nonexistence of facilities and equipment. Without correct programming, most children did not boast in basic movement development skills.

According to the study's result, an important factor about the educational program in growth in movement development skills is providing a correct program for children growth. The quality of the program does have an influential role in growth. We should provide a program in which includes a spread range of skills and be a motivational factor for activating children and is the quality factor of growth.

Unfortunately, most time of children has been filled with computer games. In similar research, we have found current children are interested in mental games without body movement development. This game has been substituted by active games and pays more to tiny movement development. As a result, great movement development skills do not been applied. According to the study result, we indicate active children could not strengthen this aspect of growth because of noncontributing in feasible activity and by required contents for growing movement development skills. Although they move, unfortunately, this activity does not have any effect on movement development growth and lingual development, too.

\section{Conclusion}

Current research result shows language development does have a close relation to movement development growth in childhood and are influenced from each other. This relation is more meaningful in 5-6 years old to language development and in the 8-7 years old is more meaningful to tiny movement development growth. Also, there is no meaningful relation between language development and activity of active children and non-active.

\section{Conflict of Interest}

The authors declared no conflict of interest. 


\section{References}

Baghande, H., Homaniyan, D., Arab Ameri, E. (2015). Effect of perceptual-motor training on motor skills of girls with trainable mental retardation. Journal of Motor Learning and Movement, 7(4), 473-490.

Burton, A. V., Miller, D. E. (1998). Movement skill assessment. Champaign, IL: Human Kinetic.

Cheng, H. C., Chen, H. Y., Tsai, C. L., Chen, Y. J., \& Cherng, R. J. (2009). Comorbidity of motor and language impairments in preschool children of Taiwan. Research in Developmental Disabilities, 30(5), 1054-1061.

Cheraghi, F., Shokri, Z., Roshanaei, G., \& Khalili, A. (2021). Effect of age-appropriate play on promoting motor development of preschool children. Early Child Development and Care, 1-12.

Dehghanizade, J., Rahmati Arani, M., Heydari, M. (2018). the effect of Braitonic exercise on the motor skills of educable children with intellectual disability. JOEC, 18(1), 85-96.

Devinsky, O., \& D'esposito, M. (2003). Neurology of cognitive and behavioral disorders. England: Oxford University Press.

Dworkin, J. P., \& Culatta, R. A. (1985). Oral structural and neuromuscular characteristics in children with normal and disordered articulation. Journal of Speech and Hearing Disorders, 50(2), 150-156.

Gandotra, A., Kotyuk, E., Szekely, A., Kasos, K., Csirmaz, L., \& Cserjesi, R. (2020). Fundamental movement skills in children with autism spectrum disorder: A systematic review. Research in Autism Spectrum Disorders, 78, 101632.

Gümüşdağ, H. (2019). Effects of pre-school play on motor development in children. Universal Journal of Educational Research, 7(2), 580-587.
Güven, S., \& Topbaş, S. (2014). Adaptation of the Test of Early Language Development-(TELD-3) into Turkish: Reliability and validity study. International Journal of Early Childhood Special Education, 6(2), 151-176.

Harrow, A. (1972). A Taxonomy of Psychomotor Domain: A Guide for Developing Behavioral Objectives. New York: David McKay.

Jenabi, M.S., Ashayeri, H., Kasbi, F., \& Amiri Shoki, Y. (2004). Comparative determination of tiny movement skills in natural child and Childs by speech disorder 7-10 yeras old referring to speech cure clinic in Iran medicine science university and hygiene services. Medicine and Purification, 51, 25-31

Loprinzi, P. D., \& Cardinal, B. J. (2011). Measuring children's physical activity and sedentary behaviors. J Exerc Sci Fit, 9(1), 15-23.

Meister, I. G., Boroojerdi, B., Foltys, H., Sparing, R., Huber, W., \& Töpper, R. (2003). Motor cortex hand area and speech: implications for the development of language. Neuropsychologia, 41(4), 401-406.

Payne, V. G., \& Isaacs, L. D. (2020). Human motor development: A lifespan approach. $11^{\text {th }}$ edition, Routledge.

Pangrazi, R. P., \& Beighle, A. (2019). Dynamic physical education for elementary school children. Human Kinetics Publishers.

Piaget, J. (2015). The grasp of consciousness (psychology revivals): action and concept in the young child. Psychology Press.

Rostami, R., \& Ghaedi, M. (2017). Core stabilization training and fundamental motor skills in children. International Journal of School Health, 4(1), 1-5.

Visscher, C., Houwen, S., Scherder, E. J., Moolenaar, B., \& Hartman, E. (2007). Motor profile of children with developmental speech and language disorders. Pediatrics, 120(1), 158-163. 